\title{
META-ANALYSIS OF PREVALENCE OF WHEEZING AND RECURRENT WHEEZING IN INFANTS
}

Ismael Alvarez-Alvarez ${ }^{1}$, Hao $\mathrm{Niu}^{1}$, Francisco Guillen-Grima ${ }^{1,2,3}$, Ines Aguinaga-Ontoso ${ }^{1}$

${ }^{1}$ Department of Health Sciences, Public University of Navarre, Pamplona, Spain

${ }^{2}$ IDISNA, Navarra’s Institute for Health Research, Pamplona, Spain.

${ }^{3}$ Preventive Medicine, University of Navarra Clinic

Corresponding author:

Ismael Alvarez Alvarez

Department of Health Sciences. Public University of Navarre.

Avenida de Barañain, s/n 31008 Pamplona (Navarra) Spain

Public University of Navarre. (Spain)

E-mail: alvarez.80114@e.unavarra.es

This is an accepted manuscript published online by Elsevier España in Allergologia et Immunopathologia on 19 August 2016.

This work should be cited as:

Alvarez-Alvarez I, Niu H, Guillen-Grima F, Aguinaga-Ontoso I. Meta-analysis of prevalence of wheezing and recurrent wheezing in infants. Allergol Immunopathol (Madr) 2018; 46(3): 210-217.

(C) 2016. This manuscript version is made available under the CC-BY-NC-ND

4.0 license http://creativecommons.org/licenses/by-nc-nd/4.0/ 


\section{Abstract}

Background: Wheezing affects children's quality of life, and is related with asthma in childhood. Although prevalence of wheezing has been previously studied in several countries, there are no reference of worldwide prevalence in infants. The aim of this meta-analysis is to estimate the prevalence of wheezing and recurrent wheezing in infants aged up to two years, and compare the prevalence across world regions.

Methods: Literature search was conducted in MEDLINE and SCOPUS databases, looking for observational studies published up to June 2016, including as keywords "prevalence” or “epidemiology” combined with “wheeze”, “wheezing” or “asthma symptoms” and "infant” or “preschool”. Fast*Pro software and random effects Bayesian model were used. Heterogeneity was estimated using $\mathrm{I}^{2}$ statistic, and sensitivity analyses were performed.

Results: We identified 109 studies after duplicates were removed. After exclusions, 14 studies were included in the meta-analysis. Prevalence of wheezing and recurrent wheezing were $36.06 \%$ (95\% CI 35.17-36.96), and 17.41\% (95\% CI 16.74-18.09), respectively. In European countries, prevalence of wheezing was 30.68\% (95\% CI 28.97-32.45), and 12.35\% (95\% CI 11.27-13.47) for recurrent wheezing. Prevalence of wheezing and recurrent wheezing in Latin America were higher, 40.55\% (95\% CI 39.40-41.71), and 19.27\% (95\% CI 18.44-20.11), respectively. In Africa, prevalence of wheezing was $15.97 \%$ (95\% CI 14.05-18.00). Low or no heterogeneity was found in all cases.

Conclusions: More than one third of infants suffer from wheezing and almost one fifth from recurrent wheezing, being these illnesses especially prevalent in Latin American countries, pointing out an important public health problem.

Keywords: epidemiology, infants, meta-analysis, prevalence, recurrent wheezing, wheezing 


\section{INTRODUCTION}

Wheezing in infants not only affects children's quality of life (1), but is related to the development of asthma childhood (2). Several risk factors, as viral respiratory infections (3), prenatal and postnatal tobacco smoke exposure (4), familiar history of asthma (5), or pollution (6) have been previously identified.

Prevalence of asthma and wheezing in schoolchildren and adolescents has been studied in the past. The International Study of Asthma and Allergies in Childhood (ISAAC) found highest prevalence of wheezing in children in United Kingdom, Oceania and Latin American countries (7). In the Phase III of the same study, increasing trends were found in countries which showed lower prevalence in Phase I, while in the Oceanian countries decreasing trends were found (8).

More recently, the International Study of Wheezing in Infants (Estudio Internacional de Sibilancias en Lactantes in Spanish, or EISL), a multicentre study in European and Latin American countries, was conducted to determine the prevalence, severity and risk factors for wheezing in infants (9).

However, no previous studies about the worldwide prevalence of wheezing in infants have been conducted. Therefore, the aim of this meta-analysis is to estimate the prevalence of wheezing and recurrent wheezing in infants aged up to two years, and compare the prevalence across different world regions.

\section{MATERIALS AND METHODS}

This meta-analysis has been conducted according to the Preferred Reporting Items for Systematic Reviews and Meta-Analyses (PRISMA) statement (10), and its protocol has been registered in PROSPERO (reference CRD42016039446). 


\section{Search strategy and selection criteria}

The literature search was performed in MEDLINE and SCOPUS databases, looking for observational studies published up to June 2016.

Search terms were "prevalence” or "epidemiology” (title), combined with "wheeze”, wheezing” or "asthma symptoms" (title), and "infant” or "preschool” (topic). The search terms were combined with Boolean search function “and”. No language filters were used.

Studies were included in the meta-analysis if they met the following criteria: 1) Original community-based studies; 2) Participants aged up to 2 years; 3) Wheezing and/or recurrent wheezing were defined; 4) Provided original data on the prevalence of wheezing and/or recurrent wheezing.

The search was complemented by reviewing the references of the selected articles to identify additional studies. In those cases that we could not have technical access, we requested the article through the Public University of Navarre library to other institutions. Two researchers (I.A.A. and H.N.) conducted the search and evaluate the studies, resolving the discrepancies by discussion.

After excluding duplicates, 109 articles were found. Reviews, pool studies, studies which not provided wheezing cases or its study population was older than two years were excluded. Abstracts and non-published studies were also excluded.

Studies quality was assessed using the Quality Assessment Tool for Observational and Cross-Sectional Studies, developed by the National Heart, Lung and Blood Institute (NHLBI) (11). We assigned one point to positive answers, and zero points to negative answers, calculating the percentage. 
Low, medium and high quality studies were those which scored less than $50 \%$, between $50 \%$ and $75 \%$, and more than $75 \%$, respectively. Low quality studies were removed from the analysis.

\section{Data extraction}

Two researchers (I.A.A. and H.N.) conducted the data extraction, resolving the differences by consulting other researcher (F.G.G.). The following data were recorded from each article: 1) Author's name and year of publication; 2) Country where the study was conducted; 3) Definition of wheezing and/or recurrent wheezing; 4) Age range; 5) Number of participants in the study; 6) Wheezing and/or recurrent wheezing cases.

\section{Quantitative analysis (meta-analysis)}

Separate meta-analyses were conducted for wheezing and recurrent wheezing in infants. Besides, we conducted additional meta-analyses for world regions (Europe, Latin America and Africa). Fast*Pro software was used to make the calculations. We used a random effects Bayesian model, showing 95\% credibility intervals (95\% CI).

In Bayesian analysis, credibility intervals are different from confidence intervals of the frequentist statistics. 95\% credible interval means that the probability that the real value is in the range of the $95 \%$, according to our initial belief and the observed data. However, a 95\% confidence interval indicates that in many repeated samples, 95\% of the intervals will show a true value.

Sensitivity analyses were performed, replicating the results after excluding studies with the lowest and highest prevalence, to study the robustness of the analysis and the influence of the removed study. To estimate the heterogeneity, $\mathrm{I}^{2}$ statistic was used, estimating the percentage of total variability between studies explained by heterogeneity (12). 
The risk of publication bias was assessed graphically by a funnel plot.

Although no wheezing definition were specified, Dela Bianca et al (18), Ferreira et al (23) and Moraes et al (24) used the written questionnaire from the EISL study, considering wheezing definitions from this questionnaire (13). Bueso et al (17) provided data from both Honduras and El Salvador EISL studies, which were separately included in this meta-analysis. Recurrent wheezing was defined as three or more episodes of wheezing by all the studies.

\section{RESULTS}

We identified 148 studies (94 in MEDLINE and 54 in SCOPUS). After duplicates were removed, we reviewed 109 studies. We excluded 59 studies whose title and/or abstract were not relevant (47 in MEDLINE and 12 in SCOPUS). Of the remaining 50 studies, 14 studies were excluded because they were reviews or pooled studies, studied risk factors for wheezing but did not provide prevalence data, did not define the outcome or provide wheezing cases, and were not community-based studies (14 in MEDLINE), and 28 were excluded because their study population was older than two years old (25 in MEDLINE and 3 in SCOPUS). Finally, eight studies were included (15, 16, 18-20, 22-24).

After examining the studies included, we identified and added six studies from the references $(14,17,21,25,26)$. Finally, 14 studies were included in the meta-analysis. (Figure 1) Of these, 11 defined and provided recurrent wheezing cases, and were included in the metaanalysis of recurrent wheezing.

Study characteristics are shown in Table 1. Studies were conducted in Brazil, Honduras, El Salvador, Spain, Netherlands, Ethiopia and Tanzania. All were cohort studies, population ranged between 673 and 3003 subjects, and their participants' age ranged between 12 and 24 months. 
Table 1. Characteristics of the studies included in the meta-analysis.

\begin{tabular}{|c|c|c|c|}
\hline Author, year & Country & Wheezing definition & RW definition \\
\hline Sunyer et al, 2001 (14) & Tanzania & Has your child ever been wheezing or whistling in the chest? & - \\
\hline Chong Neto et al, 2007 (15) & Brazil & $\begin{array}{l}\text { Has your baby had wheezing in the chest or bronchitis or whistling during his/her } \\
\text { first } 12 \text { months of life? }\end{array}$ & $\begin{array}{l}3 \text { or more } \\
\text { episodes }\end{array}$ \\
\hline Belyhun et al, 2010 (16) & Ethiopia & Has your child ever had wheezing or whistling in their chest? & - \\
\hline Bueso et al, 2010 (17) & Honduras & $\begin{array}{c}\text { Has your child had wheezing or whistling in the chest } \\
\text { during the } 12 \text { months of his/her life? }\end{array}$ & $\begin{array}{l}3 \text { or more } \\
\text { episodes }\end{array}$ \\
\hline Bueso et al, 2010 (17) & El Salvador & $\begin{array}{l}\text { Has your child had wheezing or whistling in the chest } \\
\text { during the } 12 \text { months of his/her life? }\end{array}$ & $\begin{array}{l}3 \text { or more } \\
\text { episodes }\end{array}$ \\
\hline Dela Bianca et al, 2010 (18) & Brazil & $\begin{array}{c}\text { Has your baby had wheezing or whistling in the chest } \\
\text { during his/her } 12 \text { months of life? }\end{array}$ & $\begin{array}{l}3 \text { or more } \\
\text { episodes }\end{array}$ \\
\hline Visser et al, 2010 (19) & Netherlands & Has your child ever wheezed during the first twelve months of his/her life? & $\begin{array}{l}3 \text { or more } \\
\text { episodes }\end{array}$ \\
\hline Medeiros et al, 2011 (20) & Brazil & $\begin{array}{l}\text { Has your baby had wheezing in the chest or bronchitis } \\
\text { or whistling during his/her first } 12 \text { months of life? }\end{array}$ & - \\
\hline $\begin{array}{l}\text { Pellegrini-Belinchon } \\
\text { et al, } 2012(21)\end{array}$ & Spain & $\begin{array}{l}\text { Has your child experienced wheezing or whistling in the chest } \\
\text { in the first } 12 \text { months of life? }\end{array}$ & $\begin{array}{l}3 \text { or more } \\
\text { episodes }\end{array}$ \\
\hline Costa Bessa et al, 2014 (22) & Brazil & Presence of wheezing or bronchitis in the first 12 months of child's life & $\begin{array}{l}3 \text { or more } \\
\text { episodes }\end{array}$ \\
\hline Ferreira et al, 2014 (23) & Brazil & $\begin{array}{l}\text { Has your baby had wheezing or whistling in the chest or bronchitis } \\
\text { in the last } 12 \text { months? }\end{array}$ & $\begin{array}{l}3 \text { or more } \\
\text { episodes }\end{array}$ \\
\hline Moraes et al, 2014 (24) & Brazil & Has your baby ever wheezed in the first 12 months of life? & $\begin{array}{l}3 \text { or more } \\
\text { episodes }\end{array}$ \\
\hline $\begin{array}{l}\text { Bercedo-Sanz et al, } 2015 \\
\text { (25) }\end{array}$ & Spain & $\begin{array}{c}\text { Has your child experienced wheezing or whistling sounds in the chest in the first } 12 \\
\text { months of life? }\end{array}$ & $\begin{array}{l}3 \text { or more } \\
\text { episodes }\end{array}$ \\
\hline $\begin{array}{c}\text { Alvarez-Alvarez et al, } 2016 \\
\text { (26) }\end{array}$ & Spain & Has your child wheeze in the first 12 months of his/her life? & $\begin{array}{l}3 \text { or more } \\
\text { episodes }\end{array}$ \\
\hline
\end{tabular}

RW: recurrent wheezing 
Quality assessment showed four studies $(18,20,21,25)$ with medium quality, and the rest (14-17, 19, 22-24, 26) with high quality. Therefore, no studies were removed from the analysis.

Results of the meta-analysis of wheezing and recurrent wheezing are presented in Table 2 and Figure 2. The prevalence of wheezing in infants was 36.06\% (95\% CI 35.17-36.96). No heterogeneity between the studies was found $\left(\mathrm{I}^{2}<0\right)$. Sensitivity analyses were conducted, removing the Ferreira et al study (23), finding the prevalence was 35.27\% (95\% CI 34.3636.19), with no heterogeneity $\left(\mathrm{I}^{2}<0\right)$. On the other hand, when the Belyhun et al study (16) was excluded, prevalence was 37.42\% (95\% CI 36.48-38.36), showing a low heterogeneity $\left(\mathrm{I}^{2}=5.98\right)$.

The prevalence of recurrent wheezing was 17.41\% (95\% CI 16.74-18.09). The estimated heterogeneity was $\mathrm{I}^{2}=15.81$, a low heterogeneity. When sensitivity analyses were conducted, prevalence of recurrent wheezing did not vary substantially. Prevalence when the Dela Bianca et al study (18) was removed from the analysis was $16.72 \%$ (95\% CI 16.04-17.42), finding low heterogeneity $\left(\mathrm{I}^{2}=3.15\right)$. When we excluded the Alvarez-Alvarez et al study (26), prevalence was $18.00 \%$ (95\% CI 17.29-18.73), also showing a low heterogeneity $\left(\mathrm{I}^{2}=18.72\right)$.

Results of the meta-analyses of prevalence of wheezing across regions (Europe, Latin America and Africa) are shown in Figure 3. In European countries, prevalence of wheezing and recurrent wheezing were 30.68\% (95\% CI 28.97-32.45) and 12.35\% (95\% CI 11.27-13.47), respectively. In both cases, no heterogeneity was revealed $\left(\mathrm{I}^{2}<0\right)$. In Latin America, prevalence of wheezing, 40.55\% (95\% CI 39.40-41.71), and recurrent wheezing, 19.27\% (95\% CI 18.4420.11), were higher than in Europe, showing a low heterogeneity $\left(I^{2}=7.65\right.$, and $I^{2}=7.30$, respectively). In African countries, prevalence of wheezing in infants was $15.97 \%$ (95\% CI 14.05-18.00), not evidencing heterogeneity $\left(\mathrm{I}^{2}<0\right)$.

The funnel plot did not indicate publication bias (Figure 4). 
Table 2. Meta-analysis of the prevalence of wheezing and recurrent wheezing in infants.

\begin{tabular}{cccccccc}
\hline & & \multicolumn{3}{c}{ Wheezing } & \multicolumn{2}{c}{ Recurrent wheezing } \\
\hline Author & Age range & Cases & Population & Prevalence (95\% CI) & Cases & Population & Prevalence (95\% CI) \\
\hline Sunyer et al (14) & 18 months & 148 & 673 & $22.07 \%(18.66-25.75)$ & - & - & - \\
Chong Neto et al (15) & $12-15$ months & 1364 & 3003 & $45.44 \%(43.06-47.88)$ & 678 & 3003 & $22.59 \%(20.93-24.33)$ \\
Belyhun et al (16) & 1 year & 103 & 899 & $11.51 \%(9.40-13.83)$ & - & - & - \\
Bueso et al (Honduras) (17) & $12-15$ months & 216 & 780 & $27.76 \%(24.18-31.57)$ & 91 & 780 & $11.73 \%(9.45-14.25)$ \\
Bueso et al (El Salvador) (17) & $12-15$ months & 431 & 1047 & $41.21 \%(37.42-45.19)$ & 193 & 1047 & $18.48 \%(15.97-21.18)$ \\
Dela Bianca et al (18) & $12-15$ months & 467 & 1014 & $46.11 \%(42.02-50.38)$ & 270 & 1014 & $26.68 \%(23.59-29.95)$ \\
Visser et al (19) & 13 months & 312 & 1115 & $28.03 \%(25.01-31.22)$ & 149 & 1115 & $13.41 \%(11.35-15.64)$ \\
Medeiros et al (20) & $12-15$ months & 466 & 1071 & $43.56 \%(39.69-47.60)$ & - & - & - \\
Pellegrini-Belinchon et al (21) & 12 months & 242 & 750 & $32.33 \%(28.39-36.53)$ & 89 & 750 & $11.93 \%(9.59-14.53)$ \\
Costa-Bessa et al (22) & $12-15$ months & 1024 & 2732 & $37.50 \%(35.24-39.83)$ & 444 & 2732 & $16.27 \%(14.79-17.82)$ \\
Ferreira et al (23) & $12-24$ months & 499 & 1028 & $48.59 \%(44.42-52.94)$ & 246 & 1028 & $23.98 \%(21.08-27.06)$ \\
Moraes et al (24) & $12-15$ months & 294 & 1060 & $27.78 \%(24.70-31.05)$ & 135 & 1060 & $12.78 \%(10.72-15.02)$ \\
Bercedo-Sanz et al (25) & $12-15$ months & 313 & 958 & $32.72 \%(29.20-36.45)$ & 137 & 958 & $14.35 \%(12.05-16.85)$ \\
Alvarez-Alvarez et al (26) & $12-15$ months & 327 & 1065 & $30.75 \%(27.51-34.17)$ & 106 & 1065 & $10.00 \%(8.19-11.99)$ \\
Meta-analysis & & & & & & \\
& & 6206 & 17095 & $36.06 \%(35.17-36.96)$ & 2538 & 14552 & $17.41 \%(16.74-18.09)$ \\
\hline
\end{tabular}




\section{DISCUSSION}

The present meta-analyses evidenced that wheezing in infants is a public health burden, affecting more than one third of infants, with nearly one fifth of infants who are recurrent wheezers, being these illnesses especially prevalent in Latin America. Sensitivity analyses did not substantially change the results when studies were removed, and there was no heterogeneity or was low, thus the meta-analysis seems to be robust.

Previously global studies, as the Phase I and III of the ISAAC study, found a mean prevalence of wheezing in schoolchildren of $11.8 \%$ and $11.5 \%$, respectively $(7,27)$, lower than our results. However, ISAAC study included much more centres than our analysis, and the higher incidence of wheezing in the first three years of life (28), could explain our results.

A previous European study found higher prevalence of wheezing, ranging from $29 \%$ to 48\% in North and South European countries, respectively, in children aged 1-5 years (29). A possible reason to explain the differences might be its different study population and methodology.

In Latin America, more than $40 \%$ of infants had wheezing in the first two years of life, and almost 20\% were recurrent wheezers. Our results are slightly higher than others from a recent study, which found prevalences of wheezing and recurrent wheezing in the first year of life of $39.9 \%$ and $16.6 \%$, respectively (30).

Only two African studies were included in the meta-analysis. Prevalence of wheezing in this continent was almost 16\%, higher than results from Phase III of ISAAC (27), although the low number of studies included could have led to a wrong estimation.

The analysis showed differences in the prevalence of wheezing and recurrent wheezing across world regions, finding the highest prevalences in Latin America. 
Garcia-Marcos et al found that socioeconomic factors had a major impact in this region (31). Lower parental education (32) and factors related with poverty, dirt and infections (33) have been also associated with higher prevalence of wheezing in children.

Another explanation to the higher prevalence found in Latin America compared to Europe could be the African ancestry, which has been found as risk factor for recurrent wheezing (34).

According to the World Health Organization, low and middle-income countries in Latin American region showed higher pollution levels than European high-income countries (35). Improvements in air quality are associated with an improved lung-function development (36), and consequently with a lower risk of asthma (37), which might be another possible reason.

Parasitic infections with Ascaris lumbricoides and Trichuris trichiura have been described as risk factor for wheezing in Latin American infants (38). However, findings are controversial, with other studies conducted in Africa which found a reduced risk for the disease $(39,40)$, which might partially explain the differences in the prevalence between these regions.

One of the strengths of this study is its novelty. As far as we know, there is no other meta-analysis which estimates the prevalence of wheezing in infants, providing original results with high-quality scientific evidence. Moreover, because of most of included studies defined the outcome according to the ISAAC or EISL language, the consistency of the definition is high.

Our study also has some limitations. First, there are technical limitations. We could not access other databases, which might have limited our search and findings. Second, it lacks of data from more countries. Most of Latin American and European data were from Brazil and Spain, respectively, which might not be representative of their respective world regions. Third, only two African studies were included, and we could not find any studies conducted in Asian or Oceanian countries which met the criteria, which would have improved our analysis. 
In conclusion, this meta-analysis estimate that wheezing and recurrent wheezing affect a high percentage of infants, especially in Latin American countries, who may develop asthma in later years, evidencing a public health burden. Further studies involving other countries and world regions and trends analyses would be helpful, and promoting measures addressed to preventable risk factors previously identified would be recommendable.

\section{Conflicts of interest}

The authors report no conflicts of interest. The authors alone are responsible for the content and writing of the paper. 


\section{REFERENCES}

1. Oostenbrink R, Jansingh-Piepers EM, Raat H, Nuijsink M, Landgraf JM, Essink-Bot ML, et al. Health-related quality of life of pre-school children with wheezing illness. Pediatr Pulmonol. 2006;41:993-1000.

2. Martinez FD, Wright AL, Taussig LM, Holberg CJ, Halonen M, Morgan WJ, et al. Asthma and wheezing in the first six years of life. N Engl J Med. 1995;332:133-138.

3. Lemanske RF, Jackson DJ, Gangnon RE, Evans MD, Li Z, Shult PA, et al. Rhinovirus illnesses during infancy predict subsequent childhood wheezing. J Allergy Clin Immunol. 2005;116:571-577.

4. Gilliland FD, Li Y-F, Peters JM. Effects of maternal smoking during pregnancy and environmental tobacco smoke on asthma and wheezing in children. Am J Respir Crit Care Med. 2001;163:429-436.

5. Bjerg A, Hedman L, Perzanowski MS, Platts-Mills T, Lundbäck B, Rönmark E. Family history of asthma and atopy: in-depth analyses of the impact on asthma and wheeze in 7- to 8-year-old children. Pediatrics. 2007;120:741-748.

6. Andersen ZJ, Loft S, Ketzel M, Stage M, Scheike T, Hermansen MN, et al. Ambient air pollution triggers wheezing symptoms in infants. Thorax. 2008;63:710-716.

7. Asher MI, Anderson HR, Stewart AW, Crane J. Worldwide variations in the prevalence of asthma symptoms: the International Study of Asthma and Allergies in Childhood (ISAAC). Eur Respir J. 1998;12:315-335.

8. Pearce N, Aït-Khaled N, Beasley R, Mallol J, Keil U, Mitchell E, et al. Worldwide trends in the prevalence of asthma symptoms: phase III of the International Study of Asthma and Allergies in Childhood (ISAAC). Thorax. 2007;62:758-766. 
9. Mallol J, Garcia-Marcos L. Estudio Internacional de Sibilancias en Lactantes (EISL).

[Internet] 2016 May 25 Available from:

$\underline{\text { www.respirar.org/images/pdf/respirar/eisl_visiondeconjunto.pdf }}$

10. Moher D, Liberati A, Tetzlaff J, Altman DG, the PRISMA Group. Preferred Reporting Items for Systematic Reviews and Meta-Analyses: the PRISMA statement. PLoS Med. 2009;6:e1000097.

11. National Heart, Lung and Blood Institute. Quality Assessment Tool for Observational Cohort and Cross-Sectional Studies. [Internet] 2016 Jun 6 Available from: https://www.nhlbi.nih.gov/health-pro/guidelines/in-develop/cardiovascular-riskreduction/tools/cohort

12. Higgins JPT, Thompson SG, Deeks JJ, Altman DG. Measuring inconsistency in metaanalyses. BMJ. 2003;327:557-560.

13. Mallol J, Garcia-Marcos L, Aguirre V, Martinez-Torres A, Perez-Fernandez V, Gallardo A, et al. The International Study of Wheezing in Infants: questionnaire validation. Int Arch Allergy Immunol. 2007;144:44-50.

14. Sunyer J, Mendendez C, Ventura PJ, Aponte JJ, Schellenberg D, Kahigwa E, et al. Prenatal risk factors of wheezing at the age of four years in Tanzania. Thorax. 2001;56:290-295.

15. Chong Neto HJ, Rosario NA, Sole D, Mallol J. Prevalence of recurrent wheezing in infants. J Pediatr (Rio J). 2007;83:357-362.

16. Belyhun Y, Amberbir A, Medhin G, Erko B, Hanlon C, Venn A, et al. Prevalence and risk factors of wheeze and eczema in 1-year-old children: the Butajira birth cohort, Ethiopia. Clin Exp Allergy. 2010;40:619-626.

17. Bueso A, Figueroa M, Cousin L, Hoyos W, Martinez-Torres AE, Mallol J, et al. Povertyassociated risk factors for wheezing in the first year of life in Honduras and El Salvador. Allergol Immunopathol (Madr). 2010;38:203-212. 
18. Dela Bianca AC, Wandalsen GF, Mallol J, Sole D. Prevalence and severity of wheezing in the first year of life. J Bras Pneumol. 2010;36:402-409.

19. Visser CAN, Garcia-Marcos L, Eggink J, Brand PLP. Prevalence and risk factors of wheeze in Dutch infants in their first year of life. Pediatr Pulmonol. 2010;45:149-156.

20. Medeiros D, Silva AR, Rizzo JÂ, Sarinho E, Mallol J, Sole D. Prevalence of wheezing and associated risk factors among infants in Recife, Pernambuco State, Brazil. Cad Saude Publica. 2011;27:1551-1559.

21. Pellegrini-Belinchon J, Miguel-Miguel G, De Dios-Martin B, Vicente-Galindo E, LorenteToledano F, García-Marcos L. Study of wheezing and its risk factors in the first year of life in the Province of Salamanca, Spain. The EISL Study. Allergol Immunopathol (Madr). 2012;40:164-171.

22. Costa Bessa OAA, Leite AJM, Sole D, Mallol J. Prevalence and risk factors associated with wheezing in the first year of life. J Pediatr (Rio J). 2014;90:190-196.

23. Ferreira ICC, Wandalsen NF. Prevalence and severity of wheezing in the first year of life in the city of Santo André, Brazil. Rev Paul Pediatr. 2014;32:164-170.

24. Moraes LSL, Takano OA, Mallol J, Sole D. Prevalence and clinical characteristics of wheezing in children in the first year of life, living in Cuiabá, Mato Grosso, Brazil. Rev Paul Pediatr. 2014;32:313-319.

25. Bercedo-Sanz A, Lastra-Martinez L, Pellegrini-Belinchon J, Vicente-Galindo E, LorenteToledano F, Garcia-Marcos L. Wheezing and risk factors in the first year of life in Cantabria, Spain. The EISL study. Allergol Immunopathol (Madr). 2015;43:543-552.

26. Alvarez-Alvarez I, Niu H, Aguinaga-Ontoso I, Guillen-Grima F. Prevalence and risk factors for wheezing in infants in the region of Pamplona, Spain. Allergol Immunopathol (Madr). 2016;44:415-421. 
27. Lai CKW, Beasley R, Crane J, Foliaki S, Shah J, Weiland S, et al. Global variation in the prevalence and severity of asthma symptoms: Phase Three of the International Study of Asthma and Allergies in Childhood (ISAAC). Thorax. 2009;64:476-483.

28. Matricardi PM, Illi S, Grüber C, Keil T, Nickel R, Wahn U, et al. Wheezing in childhood: incidence, longitudinal patterns and factors predicting persistence. Eur Respir J. 2008;32:585-592.

29. Bisgaard H, Szefler S. Prevalence of asthma-like symptoms in young children. Pediatr Pulmonol. 2007;42:723-728.

30. Mallol J, Sole D, Garcia-Marcos L, Rosario N, Aguirre V, Chong H, et al. Prevalence, severity, and treatment of recurrent wheezing during the first year of life: a cross-sectional study of 12,405 Latin American children. Allergy Asthma Immunol Res. 2016;8:22-31.

31. Garcia-Marcos L, Mallol J, Sole D, Brand PLP, the EISL Study Group. International study of wheezing in infants: risk factors in affluent and non-affluent countries during the first year of life. Pediatr Allergy Immunol. 2010;21:878-888.

32. de Meer G, Reijneveld SA, Brunekreef B. Wheeze in children: the impact of parental education on atopic and non-atopic symptoms. Pediatr Allergy Immunol. 2010;21:823-830.

33. Barreto ML, Cunha SS, Fiaccone R, Esquivel R, Amorim LD, Alvim S, et al. Poverty, dirt, infections and non-atopic wheezing in children from a Brazilian urban center. Respir Res. 2010;11:167.

34. Kumar R, Tsai HJ, Hong X, Gignoux C, Pearson C, Ortiz K, et al. African ancestry early life exposures, and respiratory morbidity in early childhood. Clin Exp Allergy. 2012;42:265-274.

35. World Health Organization. WHO Global Urban Ambient Air Pollution Database. [Internet] 2016 Jun 15 Available from: http://www.who.int/phe/health_topics/outdoorair/databases/cities/en/ 
36. Gauderman WJ, Urman R, Avol E, Berhane K, McConnell R, Rappaport E, et al. Association of improved air quality with lung development in children. N Eng J Med. 2015;372:905-913.

37. Islam T, Gauderman WJ, Berhane K, McConnell R, Avol E, Peters JM, et al. Relationship between air pollution, lung function and asthma in adolescents. Thorax. 2007;62:957-963.

38. Alcântara-Neves NM, Badaro SJ, dos Santos MCA, Pontes-de-Carvalho L, Barreto ML. The presence of serum anti-Ascaris lumbricoides IgE antibodies and of Trichuris trichiura infection are risk factors for wheezing and/or atopy in preschool-aged Brazilian children. Respir Res. 2010;11:114.

39. Scrivener S, Yemaneberhan H, Zebenigus M, Tilahun D, Girma S, Ali S, et al. Independent effects of intestinal parasite infection and domestic allergen exposure on risk of wheeze in Ethiopia: a nested case-control study. Lancet. 2001;358:1493-1499.

40. Dagoye D, Bekele Z, Woldemichael K, Nida H, Yimam M, Hall A, et al. Wheezing, allergy, and parasite infection in children in urban and rural Ethiopia. Am J Respir Crit Care Med. 2003;167:1369-1373. 
Figure 1. Flow chart of the study.

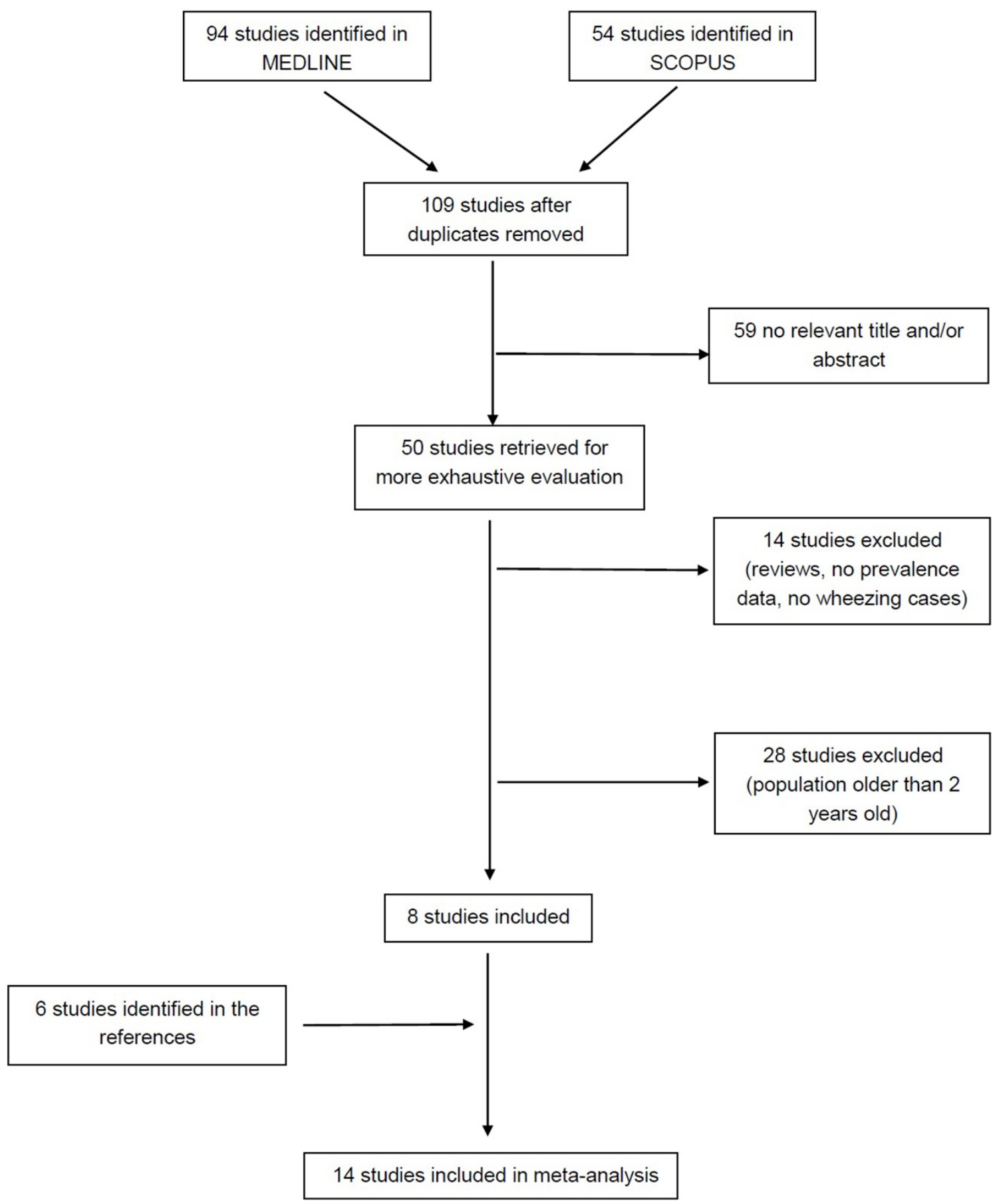


Figure 2. Meta-analysis of prevalence of wheezing (A) and recurrent wheezing (B).

A

Prevalence

$0 \% 10 \% 20 \% 30 \% 40 \% 50 \% 60 \%$

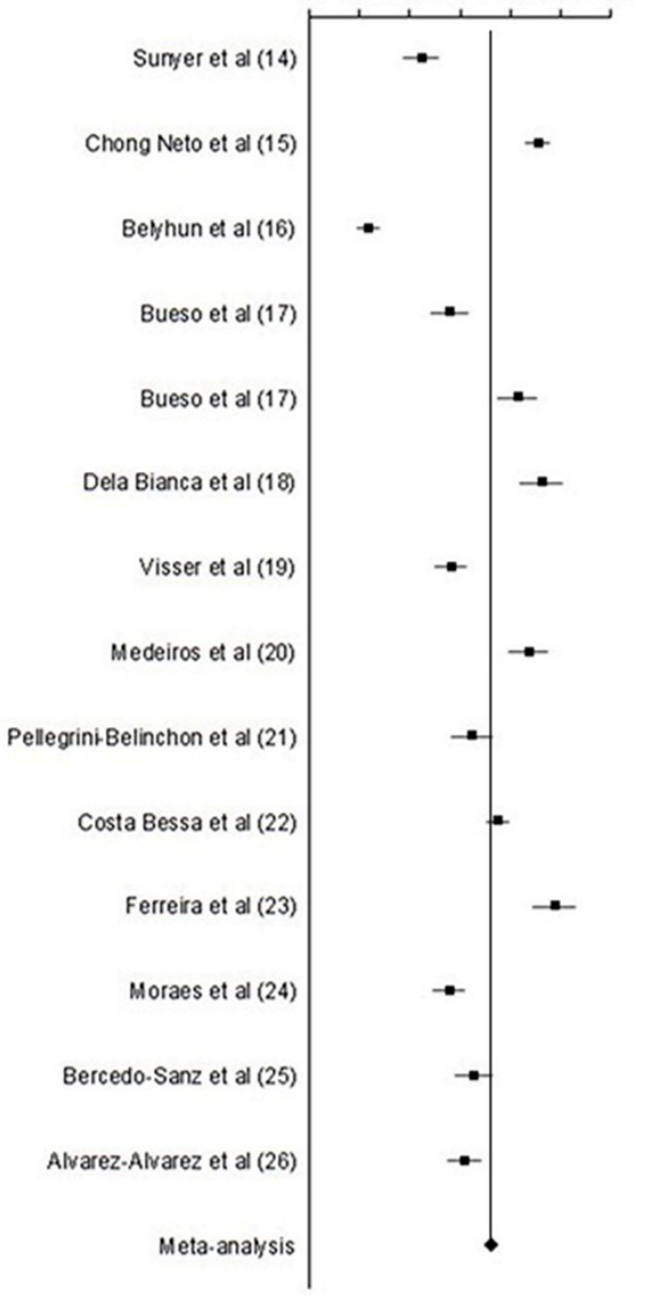

B

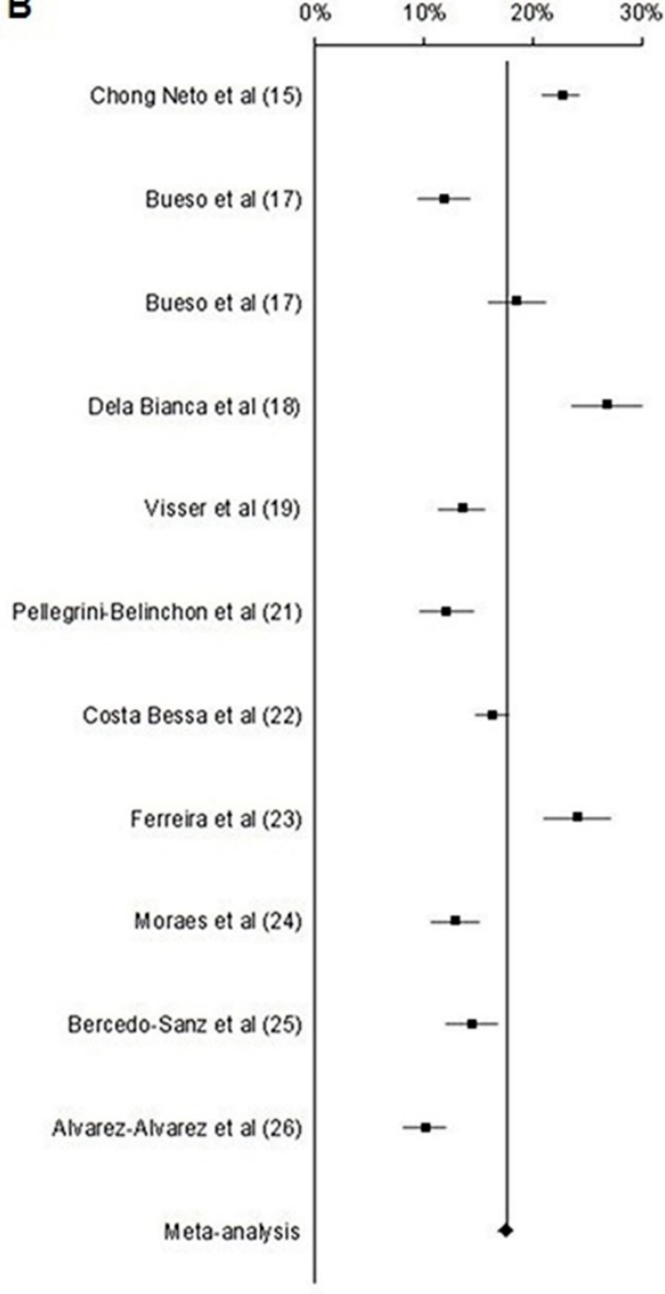


Figure 3. Meta-analysis of wheezing in infants across regions.

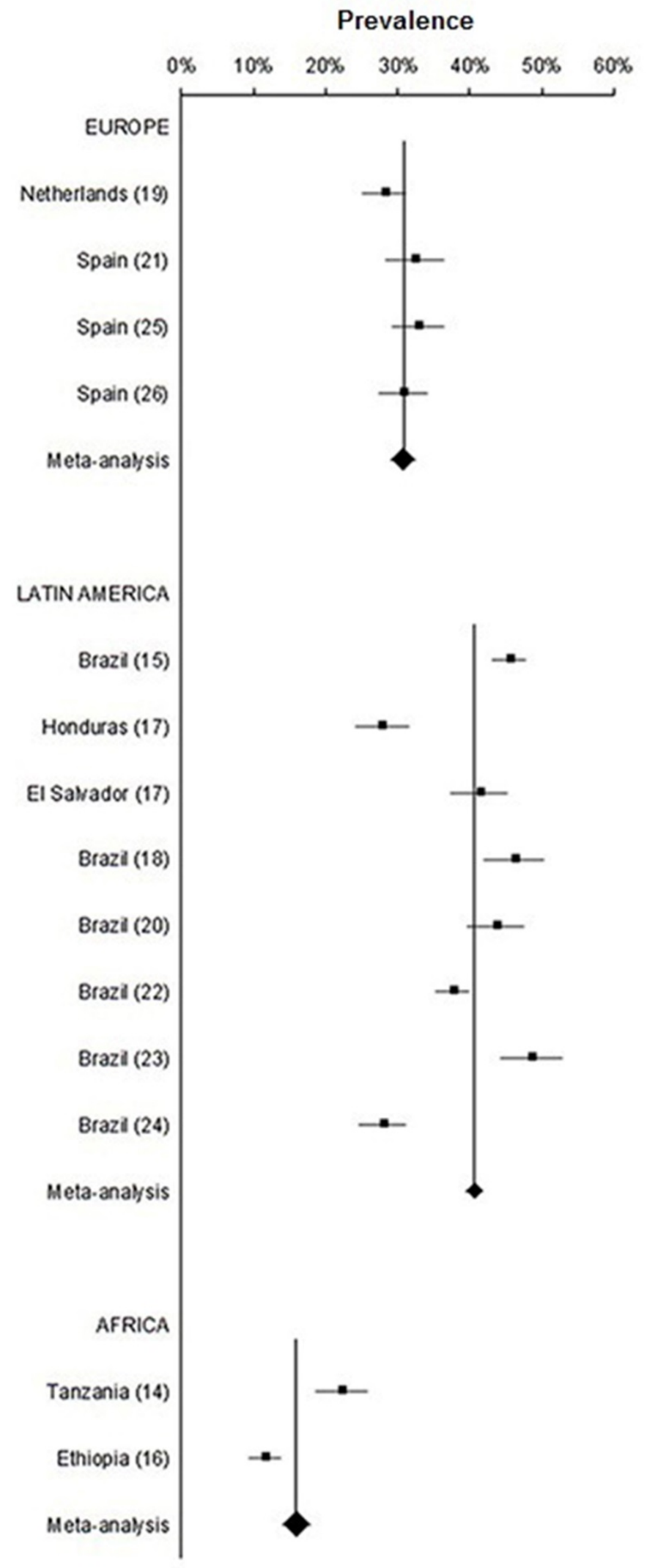


Figure 4. Funnel plot.

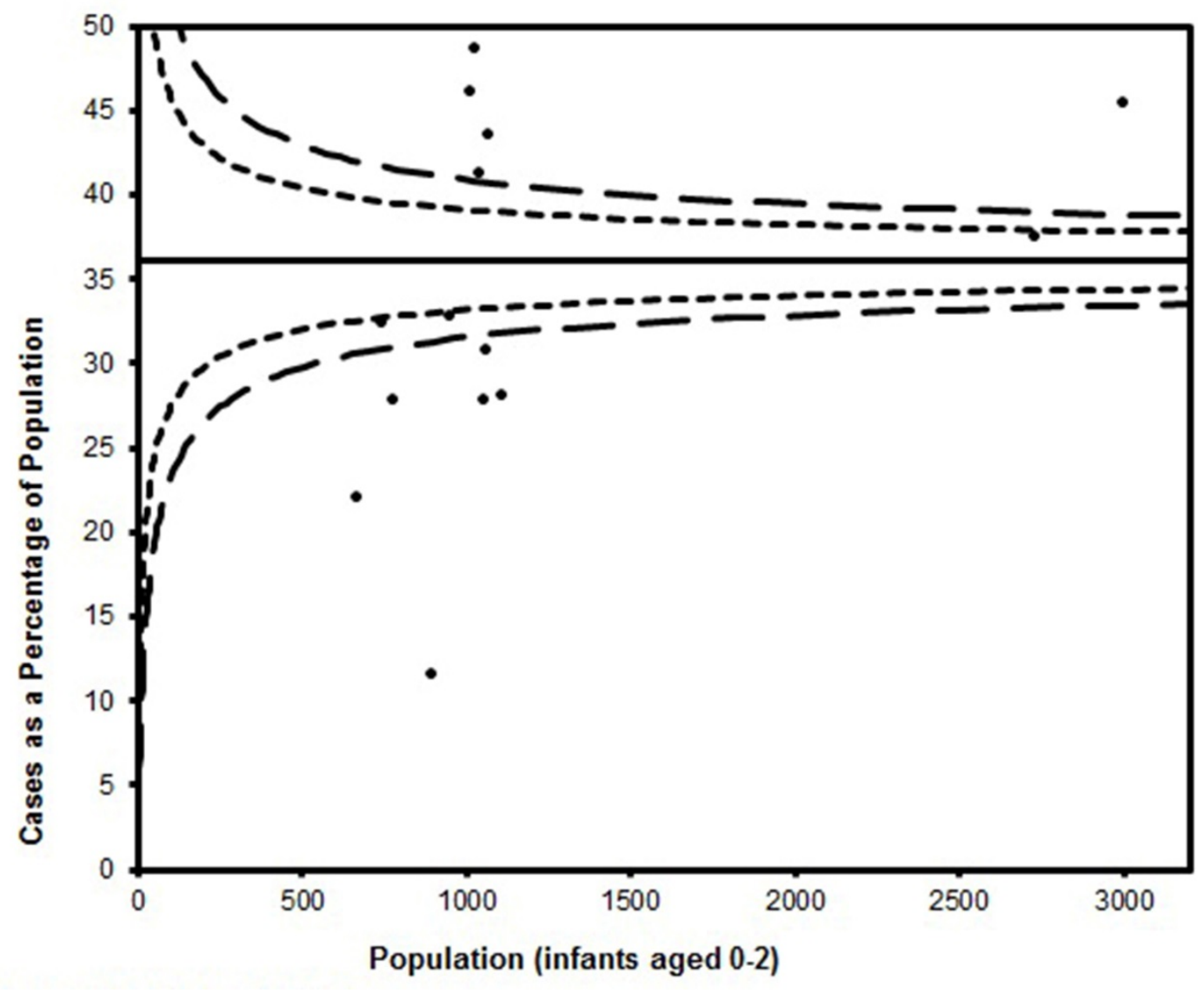

\begin{tabular}{l} 
Legend \\
\hline$\quad$ Average \\
- 2 standard deviation limits \\
The points correspond to the data. The continuous line corresponds to the average. The \\
dotted line and discontinuous line correspond to the 2 and 3 standard deviation limits, \\
respectively.
\end{tabular}

